\title{
No intervalo: a experiência do Gap Year na transição entre o secundário e a Universidade
}

\section{Crossing the gap between high school and Higher Education: the Gap Year experience}

Lígia Araújo, Ana Mouraz

\author{
CIIE, FPCE-UPorto
}

\begin{abstract}
Resumen
Num período crucial de tomada de decisão sobre o seu futuro são muitos os jovens que fazem uma pausa nos seus estudos e optam por ir viajar, explorar o mundo, fazer voluntariado, conhecer outras culturas, adiando essas decisões. No intervalo entre acabar a escola e ingressar no ensino superior, eles preferem fazer um Gap Year. Atendendo quer à dimensão desta experiência, quer à altura da vida em que ela é realizada poderá ser possível admitir que o Gap Year impulsiona de forma significativa o desenvolvimento dos jovens. É este fenómeno que pretendemos compreender com este trabalho.

Palabras clave: Gap Year, Transição, Desenvolvimento Pessoal, Universidade.
\end{abstract}

\begin{abstract}
At a time of a crucial decision making to their future many young people choose to step back from it and travel, explore the world, volunteering, learning about other cultures, postponing those decisions. In the moment between finish high school and enter higher education, they choose to take a Gap Year. Give the dimension of this experience and the moment in life it is made, maybe one's can assume that the Gap Year boosts significantly the development of young people. This is the phenomenon that we intend to understand with this paper.

Key words: Gap Year, Transition, Personal Development, College.
\end{abstract}

\section{Introdução}

Num período crucial de tomada de decisão sobre o seu futuro são muitos os jovens que fazem uma pausa nos seus estudos e optam por viajar, explorar o mundo, fazer voluntariado, conhecer outras culturas, adiando essas decisões. No intervalo entre acabar a escola e ingressar no ensino superior, eles preferem fazer um Gap Year. Atendendo quer à dimensão desta experiência, quer ao momento da vida em que ela é realizada poderá ser possível admitir que o Gap Year impulsiona de forma significativa o desenvolvimento dos jovens. É este fenómeno que pretendemos compreender com este trabalho.

O fenómeno do Gap Year tem sido estudado na literatura académica a partir de diferentes campos do saber que se tornam relevantes para a sua compreensão e impacto, como sejam os estudos sobre o turismo, a geografia, a sociologia da juventude e a educação (Snee, 2010). As questões fundamentais que estão associadas a cada uma destas áreas científicas identificam a questão do choque cultural como um aspeto relevante da experiência.

Do ponto de vista sociológico, o fenómeno Gap Year existe num contexto muito particular, associado às economias desenvolvidas e competitivas do Ocidente. E neste contexto faz sentido como experiência formativa e de desenvolvimento dos jovens como modo de sustentar o mesmo contexto que o tornou possível e desejável (Heath, 2007). Dificilmente se atribuiria a mesma designação, aos jovens que todos os dias tentam passar o Mediterrâneo para fazer o percurso inverso dos gappers.

Até que ponto os gappers são uma extensão dos antigos descobridores do século XV e XVI que levam implícita a ideia que o seu mundo e as suas formas de vida, defensoras do individualismo e da competência pessoal, são mais importantes que as locais. Até que ponto a sua experiência de contacto com outros povos subdesenvolvidos os leva a concluir que são "pobres mas felizes” impedindo com isso que o fenómeno possa ser um contributo para a mudança (Snee, 2010).

Numa leitura de cariz educativo, que é a que se privilegia neste texto, o efeito do Gap Year na vida dos gappers parte do pressuposto que a experiência é boa, que viajar está associado a uma melhoria geral do capital cultural que se tem. Nessa linha, o Gap Year emerge como um meio de ganhar vantagem competitiva sobre outros estudantes, pelo menos em contextos académicos de cariz neoliberal (Heath, 2007). Num registo semelhante, alguns estudos evidenciam que a experiência permite desenvolver competências pessoais de cariz transversal que são igualmente requeridas pelas instituições de ensino superior e pelo mercado de emprego (Heath, 2007). Essas competências transversais são de segundo nível, ou de cariz mais aprofundado, porquanto já não se trata apenas de comunicação e de relações, mas de incluir a inovação, a adaptabilidade e a transferibilidade dos saberes nos modos de pensamento, de organização e de ação próprios (Crawford \& Cribb, 2012).

Outro eixo importante a ter em conta refere-se à mudança dos modos de aprender, frequentemente associados à competência da narratividade sobre o próprio e sobre quem é que o gapper precisa fazer e ter muito claro para si mesmo. Esta consciência de si é frequentemente estimulada pelos relatos que a experiência solitária da viagem motiva e obriga (Spenader, 2011). Em paralelo, também a proficiência linguística, medida pela facilidade e eficiência na 
produção de um discurso oral, e o uso de línguas estrangeiras parecem beneficiar da experiência. São os estudantes com níveis de proficiência linguística mais desenvolvidos que experienciam maiores níveis de compreensão das culturas hospedeiras (Spenader, 2011).

$\mathrm{O}$ único estudo sistemático e extensivo sobre os gappers de um determinado país que caraterizou os sujeitos (Crawford \& Cribb, 2012) constatou que os candidatos a gappers, são na generalidade, da classe média alta e tiveram bons resultados escolares na sua experiência de ensino secundário. Mas tendem também a ser mais indecisos sobre as suas capacidades e apresentam um locus de controle externo (o que significa que tendem a pensar que as suas acções dificilmente podem fazer alguma diferença e a necessitar da reacção externa para decidirem sobre as suas ações). O mesmo estudo concluiu que os sujeitos que fazem um gap year são mais frequentemente os que não estudaram matérias associadas a cursos de ciências, tecnologia, engenharia ou matemática.

A incerteza sobre as escolhas dos cursos que se pretendem seguir no ensino superior constituem uma motivação importante para realizar um Gap Year. Tal incerteza pode resultar da baixa performatividade do percurso académico anterior (Birch \& Miller, 2007) e da baixa motivação académica para continuar a estudar (Martin, 2010) e em ambos os casos esses dois factores estão associados ao desejo de realizar um Gap Year. Contudo se a baixa motivação académica antecipa níveis de perceção de incerteza mais elevados quanto ao futuro, o desejo de realizar um gap year não se concretiza, de forma diferenciada entre os estudantes com menores resultados escolares, se comparados com os que têm bons resultados. Todavia, o estudo de Martin (2010) demonstrou que a participação num Gap Year aumenta, posteriormente, a motivação académica, que os estudantes evidenciam quando entram no ensino superior. Essa constatação pode ser explicada por uma das funções que os gappers atribuem ao Gap Year - um tempo de amadurecimento que clarifica os processos individuais de decisão e as opções de carreira (Coetzee \& Bester, 2009).

Quanto aos efeitos educativos que a literatura compulsa das experiências de Gap Year investigadas, eles organizam-se em dois grandes grupos: os efeitos no desenvolvimento individual dos gappers e os efeitos na cultura. Estes podem ser analisados de um ponto de vista mais geral e decorrem do contributo acumulado da experiência na cultura de origem, nas percepções gerais sociais sobre a experiência e seus efeitos, no sistema informal de validação e reconhecimento de competências que define as condições de empregabilidade jovem.

Os estudos compulsados, que são quase todos de dimensão empírica reduzida, são geralmente consensuais sobre o efeito direto da realização de um Gap Year e o desenvolvimento dos jovens gappers ao nível pessoal, moral, cívico, intelectual (O’Shea, 2011; Crawford \& Cribb, 2012; Spenader, 2011; Martin, 2010). Este desenvolvimento traduz-se em benefícios relativos à aquisição de competências transversais, à maior maturidade, à promoção e desenvolvimento da autoconsciência e de autonomia (Heath, 2007).
No entanto, estes mesmos efeitos adquirem depois outro sentido, quando são também preferidos pelo mercado de trabalho que irá empregar estes jovens no futuro, o que serve a perspectiva instrumental da educação (Heath, 2007). Outra corrente de autores aponta para a experiência como uma forma de aproximação cultural, realizada a partir das camadas mais promissoras da população, e de exercício de uma cidadania universal, o que se enquadra no mesmo registo dos efeitos colectivos do movimento gapper (Johan, 2009; Jones, 2004). Um último eixo de leitura que se inclui nesta análise dos efeitos gerais é relativo ao sistema educativo em geral e à educação superior em particular, que recebe os gappers, na sua quase totalidade. Se a experiência de Gap Year se desenvolve num esquema alternativo à educação formal, a pergunta pertinente é a de saber se e como os sistemas educativos validam a experiência adquirida dos gappers.

Estudar o tema numa perspectiva educacional, centrada nas motivações, nas competências desenvolvidas e nos possíveis efeitos nos percursos académicos, que é o que este texto propõe, permitirá contribuir para começar responder a esta pergunta.

\section{Método}

Este é um estudo piloto focado em quatro ex-gappers portugueses, cujo objetivo é inventariar os motivos, as competências desenvolvidas e os efeitos da experiência nos respetivos percursos académicos. O caráter piloto do estudo resulta da inexistência de estudos sobre o fenómeno na literatura académica portuguesa, em virtude da dimensão cultural que o fenómeno se reveste e o torna tão vulgar em países da Europa central e do norte.

Os casos foram selecionados a partir do conhecimento privilegiado do Presidente da Associação Gap Year Portugal que, contactado, indicou os restantes. Trata-se, por isso, de uma seleção ocasional.

Os instrumentos de recolha de dados a que se recorreu foram entrevistas aprofundadas aos jovens, antigos gappers, que frequentam agora o ensino superior, e a um membro da família ou amigo/a próximo/a de cada um deles. A opção pela recolha deste testemunho indireto resulta do conhecimento privilegiado do "antes” e do "depois" que estas pessoas têm dos "ex-gappers" porquanto testemunharam as mudanças ocorridas nestes.

A análise realizada aos dados recolhidos organizou-se a partir das três dimensões que se adequam aos objetivos do texto: motivos, competências desenvolvidas e efeitos.

As entrevistas foram analisadas através da técnica da análise de conteúdo, com recurso ao software Nvivo, versão 10.

\section{Resultados}

\section{Caraterização dos sujeitos}

Os sujeitos são quatro jovens que realizaram o Gap Year, sendo uma rapariga e três rapazes. Quanto às testemunhas, elas são familiares e amigos/as, respetivamente, duas mães e uma amiga. Um dos ex-gappers não indicou em tempo útil a pessoa que poderia constituir o testemunho do seu desenvolvimento. 


\section{Motivos}

Os quatro antigos gappers reportaram dois tipos de motivos distintos para terem adiado a entrada no ensino superior por um ano e realizarem um Gap Year. O motivo agregador dos jovens, apoiados financeiramente por uma fundação privada, foi a curiosidade e o desafio (controlado) que o repto encerrava. Um destes participantes refere que conheceu o conceito nas aulas de inglês no ensino secundário, ficou interessado no assunto, e que foi a existência de uma fundação disposta a apoiar projetos de Gap Year que lhe permitiu concretizar este sonho [D.]. Outro participante reitera a importância desta mesma fundação sublinhando a ideia do desafio [L.]. Há também outro participante que mencionou os projetos apoiados no passado pela fundação. Este factor combinado com o exemplo de um familiar - que já tinha feito um Gap Year - e o facto de ser jovem "(...) a vontade que um jovem tem com 18 anos é conhecer o mundo, é viajar...” (B.), constituem as motivações que o levaram a realizar esta experiência. A jovem entrevistada afirmou que a sua motivação se deveu a um contratempo nos seus planos académicos. “(...) o Gap Year surgiu um bocadinho como alternativa... eu não sabia bem o quê que queria fazer... o quê que poderia fazer em alternativa à Medicina.” (G.) e assim, esperava através do Gap Year “(...) preparar [me] um bocadinho mais e fazer algo que me fizesse crescer, já que naquele ano não podia entrar em Medicina” (G.). Neste caso a necessidade de se encontrar, e utilizar o Gap Year como forma de consegui-lo, é comprovado pela sua testemunha. “(...) ela estava um pouco perdida, uma vez que queria entrar para o curso de Medicina e não conseguiu... e então ficou perdida... desorientada... ficou bastante desiludida e não quis estudar nesse ano (...) andou a investigar várias hipóteses e descobriu este conceito do Gap Year..." (TG). As restantes testemunhas ressaltaram o desejo de conhecer novas culturas e pessoas como as motivações dos participantes na experiência.

\section{Competências desenvolvidas}

Na altura de nomear as competências os participantes ponderaram até que ponto aquilo que sentem se pode denominar como competência. "Para mim é difícil falar em competências, sinceramente. Eu prefiro normalmente falar naquilo que eu senti que mudou e daí se calhar tirar as competências" (L.). Assim, as competências são traduzidas nos efeitos pessoais que sentem em si próprios, após terem feito a viagem.

Vêem-se como pessoas “(...) muito mais empreendedora [s], muito mais dinâmica [s], com vontade de fazer muitas mais coisas e acima de tudo a acreditar que era[m] capaz[es] de fazer coisas ainda maiores do que aquelas a que inicialmente me[se] propunha[m]" (L.). O mesmo antigo gapper sublinhou que a experiência lhe abriu os horizontes, o ajudou a tornar-se muito mais resiliente, a ser mais responsável e a "pensar fora da caixa”. Também G. refere a abertura aos outros, o ganho de humildade, o desenvolvimento de competências de liderança e a capacidade de improvisação na resolução de problemas - o "desenrascanço"

B. refere que cresceu na época em que fez voluntariado, quando passou pela escassez de determinados bens que considerava como certos, como a escassez de água e eletricidade num local remoto em África. Reitera que adquiriu uma capacidade maior de resolver problemas e também que se tornou muito mais humilde ao contactar com pessoas que têm menos posses do que ele. No caso de D. o confronto com a diversidade também é apontado como um dos aspetos da experiência que lhe permitiu ganhar mais autonomia, mais organização, mais espírito crítico, mais competências colaborativas e de entre-ajuda. Defende que a bagagem que adquriu é importante, mas que “(...) não é algo palpável (...) é uma mais valia para o nosso currículo pessoal.” (D.).

As testemunhas dos participantes comprovaram este desenvolvimento de competências, reiterando o aumento da sua capacidade de organização, de “desenrascanço”, de responsabilidade, de superação de medos. $\mathrm{O}$ aumento do conhecimento, a melhoria das competências linguísticas e comunicacionais, e uma maior abertura e compreensão dos outros, foram outras competências e capacidades que os familiares e amigos testemunharam sobre o empoderamento que a experiência trouxe aos gappers.

\section{Efeitos no percurso académico}

Em relação ao modo como o Gap Year motivou os participantes para o seu percurso académico, estes afirmam que não só vieram mais conscientes daquilo que queriam para o futuro, como também se sentiram com mais vontade de trabalhar e estudar. “(...) é ter mais vontade de estudar, ou seja, quando eu acabei o ano [Gap Year] vim com mais vontade de estudar, porque vi que realmente a educação é algo tão bom que nós temos e porque não aproveitar e é algo que nos vai dar uma vida melhor do que aquela que às vezes nós temos...” (B.).

Este é o único ponto de diferenciação que conseguem fazer com os colegas atuais de curso, pelo facto de se sentirem mais dedicados ao estudo do que aqueles. “(...) mas eu senti uma grande diferença acima de tudo quando entrei para a faculdade, aí é que senti maior impacto. Enquanto os meus colegas muitos deles não estavam motivados para o que estavam a fazer, e não tinham muita paciência para ouvir os professores... ou gostavam de fazer barulho dentro da sala de aula... eu nunca tive esse tipo de comportamento. Porque primeiro sabia que estava no curso certo. No Gap Year aproveitei para perceber aquilo que realmente queria fazer. E depois, por outro lado estava mais maduro...” (L.). Esta motivação e maturidade e o efeito do "encontro de si mesmo" é comprovada pelas testemunhas, afirmando uma delas “(...) antes de ir era uma pessoa mais confusa em relação ao futuro e aos estudos... mas notei que quando veio, veio decidido..." (TB.). Também a testemunha de L. confirma que "apesar de ele manter o curso que queria (...) foi para esse curso (...) com muita mais motivação...”. 
Era o nosso interesse compreender se haveria alguma valorização da experiência de Gap Year por parte das instituições de ensino nas quais os antigos gappers estudam. Neste sentido questionou-se os jovens sobre qual a posição das suas instituições de ensino, e apenas G. revelou já ter participado em palestras sobre o assunto organizadas pela própria instituição. L. referiu que atualmente na sua Faculdade essa promoção não existe. Os restantes elementos entrevistados admitem que também não notam uma promoção da experiência nas suas instituições de ensino. Sobre o reconhecimento institucional das competências que o Gap Year lhes permitiu, os jovens entrevistados consideraram que as competências desenvolvidas os têm ajudado a superar com facilidade as tarefas que o ensino superior que frequentam lhes coloca.

\section{Discussão}

Ao analisar os resultados obtidos podemos afirmar que se encontram semelhanças entre o caso dos gappers portugueses e os estudos já realizados noutros países.

As motivações apresentadas em outros estudos (Snee, 2010; Martin, 2010; Jones, 2004 e O’Shea, 2011) concluiram que os jovens realizam a viagem por sentirem uma vontade de ver o mundo, de interagir com outras pessoas e culturas, de fazer uma pausa no seu percurso académico e de procurar aventura e independência. É a mesma necessidade de uma pausa, de um momento de introspeção e avaliação pessoal, procurando respostas para o seu futuro que constitui uma das motivações que impulsionou os jovens que entrevistámos a realizarem o Gap Year. Para, além disto, também o fator aventura, o ser jovem e querer explorar o mundo e conhecer mais para além do que a sua vista abarca foram outro motivador forte. Tais resultados estão em linha com as motivações encontradas na literatura.

O desenvolvimento das capacidades linguísticas, da organização, do sentido de responsabilidade e da cooperação entre indivíduos são algumas das competências encontradas nos discursos dos antigos gappers. Esta nova bagagem adquirida é muitas vezes referenciada numa terminologia bem portuguesa, o “desenrascanço". Assim, os jovens consideram que se tornaram mais aptos e mais rápidos a encontrar as soluções que precisam para as adversidades que lhes surgem. A literatura compulsada conclui pela verificação do desenvolvimento de idênticas competências. Heath (2007) relembra que a importância do Gap Year se foca no desenvolvimento de competências que poderão distinguir os jovens no mundo, denominando essas competências como as soft skills, tais como as competências comunicativas, competências organizacionais e competências de trabalho em equipa.

Mas as vantagens do Gap Year não se ficam por aqui. Snee (2010) constatou que fazer um Gap Year ajudava os jovens a lidar com contextos culturais diferentes, a expandir a mente e a adquirir uma maior compreensão sobre as diferenças culturais. No contexto do nosso estudo e em sintonia com estes resultados, encontramos a abertura dos horizontes, o aumento do respeito e da compreensão pelas diferenças culturais como valores desenvolvidos durante a experiência.

Segundo as declarações dos jovens, comprovadas pelos testemunhos, ao ingressar no ensino superior após terem realizado a experiência os jovens sentiram-se mais motivados para o trabalho universitário. O Gap Year tinha-os ajudado a compreender qual seria o melhor caminho a seguir no seu futuro, promovendo igualmente o desenvolvimento do seu empenho para com as tarefas de cariz académico. Estes resultados adequam-se às reflexões de Jones (2004) quando defendia que a participação no Gap Year podia ser interligada com um melhor desempenho educacional, sendo estes jovens mais auto disciplinados no estudo e mais motivados a cumprir os objetivos a que se proponham.

\section{Conclusões}

Analisando os contributos dos jovens portugueses que realizaram a experiência de Gap Year e as suas respetivas testemunhas, conseguimos estabelecer que motivações impulsionaram estes jovens a realizar a viagem e que competências eles desenvolveram, e também, que efeitos teve a experiência no seu percurso académico. A aventura, o desejo de ver o mundo e conhecer uma realidade diferente daquela com que convivem diariamente foram os motivos destes jovens. Com esta experiência os gappers desenvolveram um variado leque de competências que atravessam vários campos, desde o campo linguístico ao organizacional, passando pela área mais social.

Estas competências enquadram-se naquilo que a sociedade considera serem soft skills, que poderiam (ou não) ter sido desenvolvidas independentemente da realização do GAP Year, mas que a experiência tornou indispensáveis. O facto de os jovens do nosso estudo não estarem ainda no mercado de trabalho não permitiu verificar da sua aplicabilidade nesse contexto. Por outro lado e embora os entrevistados tenham considerado que as mesmas competências lhes são úteis na sua circunstância atual de estudantes do ensino superior, não é claro que a instituição que frequenta reconheça essa diferença como uma mais valia.

A experiência teve impacto no percurso académico destes jovens que ingressaram no ensino superior logo após realizarem o Gap Year. Se partiram de Portugal com um sentimento de indecisão (e num caso de frustração) sobre o seu futuro, sobre o curso tirar e com dúvidas relativamente ao que se viam a fazer na vida adulta, regressaram mais determinados e motivados. Sabem o que querem, o Gap Year ajudou-os a descobrir ou a consolidar os seus pensamentos e a decidir sobre um curso, que afirmaram ser aquilo que efetivamente são felizes a estudar. Todos eles se mostraram satisfeitos pelas escolhas que realizaram e dizem-se felizes com os seus percursos académicos.

Propusemo-nos responder se a experiência de Gap Year (que se desenvolve num esquema alternativo à educação formal) pode ser validada pelos sistemas educativos formais. Constatamos que existe um efeito positivo da experiência no desenvolvimento educativo dos jovens gappers, seja através da motivação que ganharam para os respetivos cursos, seja pelo 
desenvolvimento de competências, seja pelo acréscimo da sua bagagem cultural que lhes será útil no decorrer da sua passagem pelo ensino superior. Todavia não é claro que essa mesma diferença seja depois validada pelas instituições. Segundo os testemunhos, na maior parte das vezes as instituições nem sabem que possuem estudantes que realizaram esta experiência. Este aparente desinterese, ou falta de conhecimento sobre o fenómeno Gap Year, constata-se nas universidades, mas igualmente nas escolas de ensino secundário. Há ainda algum preconceito perante a ideia de parar os estudos e ir viajar pelo mundo, explorando, trabalhando ou fazendo voluntariado durante pequenos períodos. É possível que tal conclusão resulte da maior importância que é atribuída à certificação formal das experiências educativas que se associam à tradição cultural (característica dos países do sul da Europa) de considerar os jovens dependentes da família até à conclusão da sua formação e imediato ingresso no mercado de trabalho. A crise económica parece estar a abalar essas convicções.

Reconhecer a experiência de Gap Year como válida para facilitar as transições dos jovens para o ensino superior é uma ideia que pode ser trabalhada. Talvez o Gap Year possa ser a "pausa" capacitante antes de ingressar no mundo académico ou no mundo do trabalho. Uma pausa que tem o poder de estimular uma aproximação à diversidade cultural e à vida que espera os jovens no seu futuro.

\section{Referências}

Birch, E. B., \& Miller, P. W. (2007). The characteristics of "gap-year" students and their tertiary academic outcomes. Economic Record, $N^{o}$ 83, 329-344.
Crawford, C. \& Cribb, J. (2012) Gap year takers: uptake, trends and long term outcomes. London: Centre for Analysis of Youth Transitions (CAYT).

Coetzee, M. \& Bester, S. (2009).The possible value of a gap year: A case study. South African Journal of Higher Education, $N^{o} 23$ Vol. 3, 608-623

Heath, S. (2007) Widening the gap: pre-university gap years and the 'economy of experience'. British Journal of Sociology of Education, $N^{\circ}$ 28. Vol. 1, 89-103

Johan, N. (2009) 'Gap year travel: youth transition or youth transformation?’. In R. Brooks (ed.) Transitions from education to work: new perspectives from Europe and beyond (pp. 136-149) Basingstoke: Palgrave Macmillan.

Jones, A. (2004) Review of Gap Year Provision, Research Report No 555. London: Department for Education and Skills.

Martin, A.J. (2010). Should Students Have a Gap Year? Motivation and Performance Factors Relevant to Time Out After Completing School. Journal of Educational Psychology, $N^{\circ} 3$ Vol. 102, 561-576.

O'Shea, J. (2011). Delaying the academy: A gap year education. Teaching in Higher Education, $N^{\circ} 5$ Vol. 16, 565-577.

Snee, H. (2010). Does travel broaden the mind? A critical review of learning through the gap year. Lifelong Learning In Europe, $N^{\circ} X V$ Vol. 3, 159-168.

Spenader, J. (2011) Language Learning and Acculturation: Lessons From High School and Gap-Year Exchange Students. Foreign Language Annals, $N^{\circ} 2$ Vol. 44, 381-398. 